\title{
Prevalence and Factors associated with sickness absenteeism among Pharmaceutical Industrial workers of Hyderabad, India
}

\author{
Sudha Bala ${ }^{1}$, Rajiv Kumar B ${ }^{2}$, Harshal Pandve ${ }^{3}$ \\ ${ }^{1}$ Assistant Professor, ${ }^{3}$ Professor and Head, Department of Community Medicine, ESIC Medical College, Hyderabad, \\ India, ${ }^{2}$ Assistant Professor, Department of General Medicine, ESIC Medical College, Hyderabad, India
}

Background: Sickness absenteeism is a potential epidemiological issue leading to loss of productivity in addition to increasing the cost of health care and provides a major tool in enhancing occupational health care preventive strategies. Aim and Objectives: To determine the prevalence of sickness absenteeism and their associated factors among Industrial Workers of Pharmaceutical Manufacturing industries in Hyderabad. Materials and Methods: A cross sectional study was taken up among 160 Workers at two Pharmaceutical Manufacturing companies in Hyderabad using simple random sampling technique. Data included Individual, Occupational and Organizational factors influencing their sickness absenteeism and general health conditions in the past six months through camp based approach. Data was analysed using descriptive statistics and multinomial logistic regression analysis to predict the variables associated with the outcome. Results: The prevalence of sickness absenteeism was found among $19 \%$ of the workers. Common causes were due to sickness among $25(84 \%)$ and social responsibilities among $5(16 \%)$. On multinomial logistic regression analysis- poor superior relationships, poor co-workers relationship and high mental stress were found to be significant. Conclusion: Sickness absenteeism was found to be high which can be reduced by improving relationships with superiors and co-workers and also by reducing mental stress among the workers.

Key words: Sickness absenteeism; Industrial workers;Prevalence; Pharmaceutical; Co- workers relationship; Epidemiology; Hyderabad
Access this article online

Website:

http://nepjol.info/index.php/AJMS

DOI: 10.3126/ajms.v12i1.31211

E-ISSN: 2091-0576

P-ISSN: $2467-9100$

Copyright (c) 2021 Asian Journal of Medical Sciences

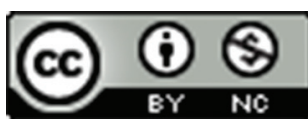

This work is licensed under a Creative Commons Attribution-NonCommercial 4.0 International License.

\section{INTRODUCTION}

Sickness Absenteeism is defined as Temporary, Extended or, Permanent incapacity for work as a result of sickness or infirmity as per Euro definition. ${ }^{1}$ This is an emerging important epidemiological health issue since it has both economic and public health implications by increasing costs of medical care and social security as well as decreased workforce thereby reduced production and economy.

International Labour Organisation reported more than 2.78 million deaths per year due to occupational accidents or work-related diseases and more than 4 days of absence from work. The economic burden of poor occupational safety and health practices is estimated at 3.94 percent of global Gross Domestic Product each year. ${ }^{2}$

Several indicators have been used to monitor absenteeism such as (i) Absence from work; (ii) Frequency of occurrence of absence; (iii) Cumulative incidence (individual frequency); and (iv) Absenteeism rate (\%). ${ }^{3}$

The International Social Security Association (ISSA) in 1981 advised to use the absenteeism rate as a monitor tool to have international comparisons. ${ }^{4}$

In the Indian scenario, the labor bureau has provisionally released the man-days lost in 2019 to be 640976, a huge number. ${ }^{5}$ Peculiar features of sickness absenteeism were 
observed in many Indian studies such as the rate was found to be low on payday, generally high among the age group of $<25$ years and $>40$ years, higher in night shift and seasonal -more during March-May where they go back to their farms for harvesting. ${ }^{6}$

It is a complex phenomenon influenced by factors other than physical health. Individual, Organizational and Occupational factors act as major predictors in estimating the outcome - The sickness absenteeism. In modern occupational health the emphasis is upon the people, the conditions in which they live and work, their hopes and fears, their attitude towards their job, their fellow workers, and employers. Interaction between person, physical and psychological working environment has a great impact on the job satisfaction.

Hyderabad serves as a hub for Pharmaceutical Industries with many of the well-known factories being located in and around the city. Sickness absenteeism data is a tool for the occupational health care services to set priority for preventive measures and evaluation of existing methods. Identification and addressing these factors helps to prevent loss of manpower, resources, and production of Industries. Therefore, the current study was conducted with an objective to assess the prevalence of sickness,absenteeism and factors associated with their absenteeism among Pharmaceutical Industrial Workers.

\section{MATERIALS AND METHODS}

\section{Study design and setting}

This Cross-Sectional study was carried out at two Pharmaceutical Industries located in the Industrial area named Jeedimetla, Hyderabad. This area is attached to our Urban Health Center catering to the health needs of the industrial population. These Pharmaceutical Industries were involved in manufacturing, packing, and distribution of essential medicines. Five pharmaceutical industries were contacted and among these, two have given permission to conduct the study. Each Industry was employing 200-300 employees working on a rotational shift system of 8 hours every day with one day weekly off.

\section{Study participants \\ Inclusion criteria}

Employees who were working in the industry from the past one year or moreand representing economically productive group of age 18-58 years with written informed consent were included in our study using Simple Random Sampling.

\section{Exclusion criteria}

Workers who were employed for less than one year and not willing to participate were excluded from our study.

\section{Sample size}

Using the formula 4PQ/ $\mathrm{L}^{2}$, where Prevalence of Sickness Absenteeism among Pharmaceutical Industrial Workers $=10 \% ;{ }^{7}$ Sample of 144 along with $10 \%$ non-response rate was calculated and the Total Sample Size was rounded off to 160 .

\section{Data collection tools}

Data was collected by trained team using pre-designed pretested questionnaire schedule consisting of sociodemographic details, personal habits; workplace information on type of work, shift hours, duration of working hours, work environment exposure to heat, noise, dust, vibration, safety, physical or any form of mental stress. Workplace Relations were assessed from the Questionnaire adopted from our Indian Study done in Steel Industry by R.Manjunath for feasibility having 1-4 Likert Scale with 5 questions about Co-Workers and Superiors each with a maximum score of $20 .{ }^{8}$ The predictor variables included were individual, occupational and organizational which were influencing the outcome-Sickness absenteeism(SA) which was operationally defined as Any worker who lost $>3$ working days due to sickness or injury in the past 12 months. ${ }^{9}$

General health information to assess common comorbidities, any hospitalization and causes of absenteeism information was probed for and further confirmation from the medical records available at the industrial personal department was acquired. This data was collected on a camp based approach for 2 months.

\section{Ethical considerations}

Institutional Ethical Clearance approval was obtained (IEC-F027/11-2017) before the Study. Heads of the Human Resource departments of concerned factories were consulted and the purpose of the study was explained in detail to seek their permission to conduct the study in their premises. Written informed consent was obtained from the participants.

\section{Statistical analysis}

Data was entered in Microsoft Excel software (2010) version and analyzed. Descriptive statistics such as frequency and mean scores were used.Independent t-test was used to depict the association between the variables and the outcome. Multinomial Regression Analysis was done to predict the variables/ factors affecting the outcomesickness absenteeism

\section{RESULTS}

Our study included 160 Pharmaceutical company employees working in different sections starting from production to distribution of medicines. 
Prevalence of sickness absenteeism among pharma industrial workers

Sickness absenteeism was found among 30(19\%) and some of the employees $29(18 \%)$ do not know the term nor the existence of such leave even after working for more than a year as detailed in Figure 1. Common reasons for sickness absenteeism were found to be sickness among 19(63\%), injury $2(7 \%)$, social responsibilities $7(23 \%)$, and family problems $2(7 \%)$.

\section{Occupational factors}

Blue-collar workers - working at production sites, and plants of the Industry were $140(87.5 \%)$, and White-collar workers - working at the office side and service side of the industry were $20(12.5 \%)$. Rotational shift work was found to be present among $60(37.5 \%)$ of the employees. The average duration of shift work was $6.72 \pm 3.246$ hours per day. History of injury at the workplace was found only among $5(3 \%)$. An independent t-test analysis depicted a statistically significant association between the shift work and mean number of workdays lost per worker detailed in Table 1.

\section{Work environment characteristics}

Individual perceptions of the working environment were graded from 'not at all' to 'high' for common work environment characteristics. Heat was perceived as Not at all 24(15\%), Less 81(51\%) Moderate 27(16.9\%) and High among 28(17.1\%); noise was Not at all among 20(12\%), Less $84(52 \%)$, Moderate 36(22\%) and High among 20(14\%); dusty environment as Not at all 19 (12\%), Less 84(52\%), Moderate 32(20\%) and High among 25(16\%); unsafe was found as Not at all among $52(32 \%)$, Less 88(56\%), Moderate $10(6 \%)$ and High among $10(6 \%)$; vibration was perceived to be Not at all among $55(34.5 \%)$, Less 82(51\%), Moderate 11(7\%) and High among 12(7.5\%). Physical and mental stress at workplace provided in Figure 2.

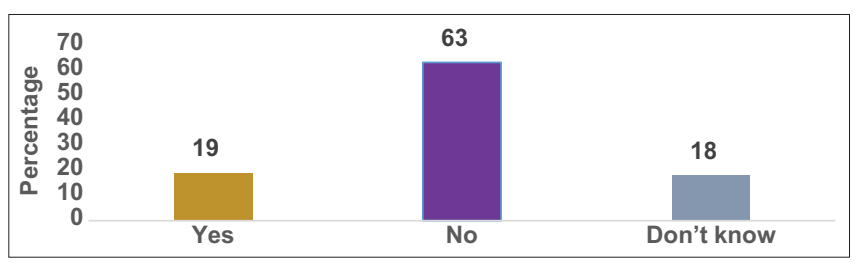

Figure 1: Prevalence of sickness absenteeism among Pharma Industrial Workers

\begin{tabular}{llc}
\multicolumn{3}{l}{$\begin{array}{l}\text { Table 1: Association betweenoccupational factors } \\
\text { and number of work days lost per worker per year }\end{array}$} \\
\hline \multicolumn{1}{l}{$\begin{array}{l}\text { Variable } \\
\text { Mean scores of sick leave }\end{array}$} & P value \\
\hline $\begin{array}{l}\text { Type of work } \\
\text { Blue collar }\end{array}$ & $1.94 \pm 5.72$ & 0.974 \\
White collar & $1.94 \pm 9.47$ & \\
Shift work & $1.20 \pm 4.02$ & 0.003 \\
No & $3.54 \pm 14.25$ & \\
Yes & & \\
\hline
\end{tabular}

\section{Individual factors}

\section{Socio-demographic characteristics}

These factories consisted of a higher proportion of males constituting to $128(80 \%)$ and females $32(20 \%)$. According to the educational status, illiterates were $38(24 \%)$, up to primary school $11(7 \%)$, the middle school $35(22 \%)$, high/ intermediate $37(23 \%)$, graduates $27(17 \%)$ and postgraduates $12(7 \%)$. Using modified BG Prasad's classification of socioeconomic status, ${ }^{10}$ the employees belonging to upper class were 41(26\%), upper middle class 49(31\%), middle class $40(25 \%)$, and upper lower class were 30(18\%). We also had employees having nuclear families 88(55\%), joint family 65(41\%), and extended family among 7(4\%).

Personal habits such as tobacco usage was among $27(17 \%)$, out of these ever users were $6(3.8 \%)$, former users $3(1.9 \%)$ and current users 18(11.3\%); Alcohol usage was found among 63(39\%). Of these ever users were 6(3.8\%), former users $8(5 \%)$ and current users $49(30.6 \%)$.

The number of dependents for these employees was found to be on an average of about 3.07 \pm 1.58 . The distance of the house from the workplace was less than 5 kilometers among 101(63.1\%), 5-10 kilometers 26(16.3\%), and greater than 10 kilometers $33(20.6 \%)$. There was a statistically significant association with gender, number of dependents and number of workdays lost per worker per year depicted in Table 2.

\section{Common health conditions * ( Multiple responses)}

Most common health conditions suffered by the employees were musculoskeletal disorders 22(55\%), Cardiovascular Diseases including hypertension $5(12.5 \%)$, coronary heart diseases $1(2 \%)$ and cerebrovascular accident $1(2 \%)$, Pregnancy-related in the form of infertility and gestational diabetes/Gynecology related problems 3 (7.5\%), injuries 2(5\%), Diabetes Mellitus 2(5\%), Alcoholic Liver Disease $1(2 \%)$, Skin disorders $1(2 \%)$, ENT problems $1(2 \%)$, Gastroenteritis 1(2\%) and Fever 1(2\%).

\section{Organizational factors}

Scoring was given under each category toassess the personal relationship of the worker with co-workers and superiors. Lower scores indicated a good relationship with co-workers and superiors. This difference was found to be statistically significant with sickness absenteeism in the past one year. Table 3.

\section{Regression analysis}

On Multinomial Regression Analysis the following predictor variables were found to be Significant with outcome-Sickness Absenteeism including Poor Co-Workers Relations (0.001), Poor Superiors Relations (0.0001) and Mental Stress (0.01) illustrated in Table 4. 


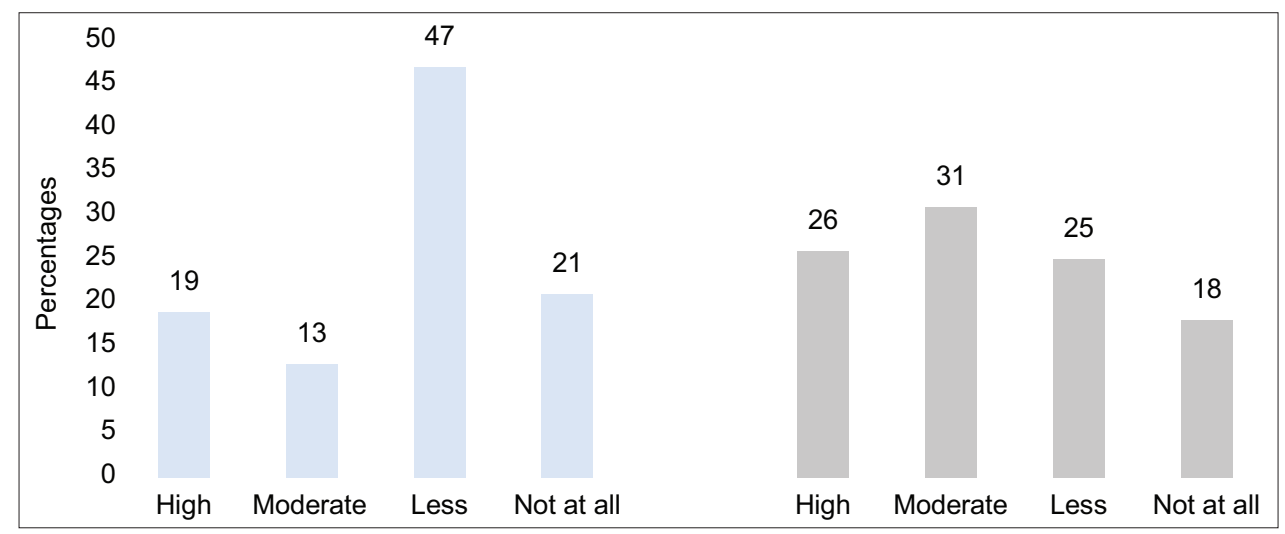

Figure 2: Individual perceptions of employees for physical and mental stress in the working environment

\begin{tabular}{|c|c|c|}
\hline Variable & Mean scores of sick leave & $P$ value \\
\hline \multicolumn{3}{|l|}{ Sex } \\
\hline Males & $0.93 \pm 3.04$ & 0.00001 \\
\hline Females & $6.25 \pm 18.90$ & \\
\hline \multicolumn{3}{|c|}{ Dependents } \\
\hline$>3$ & $1.43 \pm 4.329$ & 0.001 \\
\hline$<3$ & $0.02 \pm 0.129$ & \\
\hline
\end{tabular}

\begin{tabular}{lccc}
\multicolumn{3}{l}{ Table 3: Work place relationship scoring and } \\
sickness absenteeism & $\begin{array}{c}\text { Mean of } \\
\text { Mean of } \\
\text { score among } \\
\text { those without } \\
\text { sickness } \\
\text { absence in the } \\
\text { past 1 year }\end{array}$ & $\begin{array}{c}\text { Pcore among } \\
\text { those having } \\
\text { sickness } \\
\text { absence in the } \\
\text { past 1 year }\end{array}$ & \\
\hline pariables & $9.72 \pm 2.79$ & $9.86 \pm 3.96$ & 0.004 \\
Co-Workers & $9.36 \pm 2.44$ & $10.06 \pm 4.10$ & 0.00001 \\
\hline Superiors & & & \\
\hline
\end{tabular}

\begin{tabular}{|c|c|c|}
\hline Variables & Odds ratio ( Confidence Interval) & $P$ value \\
\hline $\begin{array}{l}\text { Poor co-workers } \\
\text { relations }\end{array}$ & $2.352(0.996-3.015)$ & 0.001 \\
\hline $\begin{array}{l}\text { Poor superiors } \\
\text { relations }\end{array}$ & $3.779(1.021-4.182)$ & 0.0001 \\
\hline $\begin{array}{l}\text { Presence of } \\
\text { mental stress }\end{array}$ & $1.012(0.501-5.102)$ & 0.01 \\
\hline
\end{tabular}

Semi-structured interview was conducted among 6 workers to elicit their views and descriptions which uncovered certain issues that have not been anticipated. Questions asked were common for these workers. These workers had no idea about the leaves or benefits which were available to them. This revealed the following views and experiences-

"Our salary was paid as per the number of working days; not paid for the days absent."
"Most of them are not aware of the number of leaves provided to them except for the day off weekly."

"No health checkups taken up for us."

"Don't even know the existing benefits for us. What are those?"

These findings help us to focus on sickness presenteeism which itself is again a factor for poor health status, affecting both the physical and mental well being of employees.

\section{DISCUSSION}

Our study included private pharmaceutical industrial workers of two well-known companies located in the Industrial Hub of Hyderabad about 12 kilometers from the city center which is divided into 6 phases.

Prevalence of sickness absenteeism in our study was found to be $19 \%$, with common reasons for availing this as sickness $63 \%$, social responsibilities $23 \%$ followed by family problems $7 \%$, and injury $7 \%$.

The prevalence of sickness absenteeism among European countries stands to be very low in Greece $(6.7 \%)$, $\operatorname{Ireland}(8.3 \%)$ and $\operatorname{Italy}(8.5 \%) .{ }^{11}$

Rashmi Tiwari in Raipur found common reasons for sickness as family and health problems (54.5\%), mental stress $22.7 \%$, and occupational problems $(4.5 \%) .{ }^{12}$ Janapriya et al in steel utensils manufacturing unit located in Tamil Nadu observed main causes for employee absenteeism as unexpected situation $33.5 \%$, for other reason $22.5 \%$, festival/function $16.5 \%$, stress $15 \%$ and $12.5 \%$ for health issues. ${ }^{13}$

All these variations can be explained by different methodologies adopted by different countries especially 
High-income countries are having social insurance systems and guaranteed salary rules for sick leave with strict legal obligations.

The most important factors were- the type of work where we have more than three-fourths of blue-collar employees contributing to $87.5 \%$ where statistically significant association was found with a mean score of sick leave per annum. Mean duration of shift hours was $6.72 \pm 3.24$ hours per day contributed by $37.5 \%$ of workers. Based on the individual graded perception of the working environment, the majority of the employees experienced moderate to high mental stress among 57\% and Physical stress as $32 \%$. Females were having a statistically significant association with higher mean scores of sick leave availed. And those who were having more than 3 dependents also found a statistically significant association with higher sickness absenteeism from work. More than half of them suffered from musculoskeletal disorders followed by cardiovascular diseases and pregnancy-related complications. Organizational factors such as poor coworkers and superior's relationship played a vital role in availing increased mean scores of sick leave among our participants.

Soares Xavier in their case-control study among Brazilian petroleum industry workers found an average incidence of sick leave among $15.5 \%$. The factors that influenced this were female gender, smokers, those reported abnormal sleep, and dissatisfaction with work. ${ }^{14}$

Mekonnen in their study among flower farm industry workers of Ethiopia found SA to be very high 54.5\% in the past 12 months. Major reasons were minor illness (20.64\%), typhoid (14.53\%), and the least common cause as malaria $(2.48 \%)$. On multivariable regression analysis sex, job satisfaction and drinking alcohol were the predictors for sickness absenteeism. ${ }^{15}$

These studies have similarities with our study whereby female gender and poor job satisfaction were the predictor variables. This can be explained by the fact that most of the females engage in multiple roles at home and work thereby worsening their existing health condition. Perceived stress at work with poor organizational climate creates unhappiness towards work and so people absent themselves from work. And there is a variation of common health problems due to varying disease patterns across the countries globally.

Lei Hum wee in their study on Ante ceding factors predicting absenteeismand presenteeism of urban Malaysia found the predictorsas income, general physicalhealth, sleep length, and being unwell due to stress. ${ }^{16}$
Manjunatha $\mathrm{R}$ in their study among iron and steelworkers at Karnataka reported a statistically significant association with gender, type and shift of work availing higher number of days lost per worker per year and the common health problems noted were similar to our study where musculoskeletal disorders accounted to $31.1 \%$, gastrointestinal $(25.8 \%)$ and hypertension $(24.4 \%){ }^{8}$

Suhash Chakraborty found $42 \%$ of sickness absenteeism among urban industrial employees at Bangalore in a hospital-based study where the main problem was workplace poor inter-personal relationship (85\%), work overload (61\%) and spending more hours in a factory $(50 \%){ }^{17}$

All these can be very well explained by methodological differences and different study populations studied in different industries. But common to most of these studies discussed was the mental stress with poor relationships at workplace and physical health - a vicious cycle that was affecting the SA.

\section{CONCLUSIONS}

Our study has very well documented the significant predictors mainly poor coworkers and superior's relationships along with mental stress for the outcome. We need to bring about a cordial relationship in the workplace between superiors and colleagues. Work stress reduction by creating recreational, welfare facilities, and in-house training of personality development courses. Incentives to boost motivation for those who have good attendance. Counseling the chronic absentees using employee assistance programs, periodical medical checkups, workplace initiatives supporting ergonomic principles for postural maintenance needs to be undertaken regularly to reduce the sickness absenteeism.

The main limitation of our study is that our results cannot be generalized as data is derived from two factories only, and require regular follow up studies in the future to establish causality. The new concept of sickness presenteeism needs to be evaluated in further studies using well designed qualitative approach as it serves as one of the proven predictors of the outcome.

\section{ACKNOWLEDGEMENT}

The authors take this opportunity to thank our medicosocial workers, HR In charges of the Pharmaceutical industries and all the participants for their cooperation and support for this study. 


\section{REFERENCES}

1. Preventing absenteeism at the workplace: European research report[Internet] Grundemann RWM, Vuuren (CV): European Foundation for the Improvement of Living and Working Conditions. c1997- [cited 2020 Feb 13]. Available from: http:// www.re-integrate.eu/resources/preventing-absenteeism-at-theworkplace.pdf

2. Safety and health at work-ILO.org[Internet]. Geneva: International Labour Organization, Inc ; c 2020[updated 2020 Apr 28;cited 20209 May 3] Available from: https://www.ilo.org/ global/topics/safety-and-health-at-work/lang--en/index.htm

3. Borg K, Goine H, Soderberg E, Marnetoft SU and Alexanderson K. Comparison of seven measures of sickness absence based on data from three counties in Sweden. Work. 2006; 26:421-428.

4. International Social Security Association. Absenteeism and Social Security Studies and Research. Vol. 16 International Social Security Association; Geneva, Switzerland: 1981

5. Annual report 2018-19. Ministry of labour and employment: Government of India. C2019-.[cited 2019 Nov 21]. Available from: https://labour.gov.in/annual-reports

6. Rabiyathul Basariya S. Employee Absenteeism in Indian Industries. International Journal of Science and Research. 2015; 4: 141-156

7. Annual report 2012-13. Ministry of labor and employment. Government of India. C2013- [cited 2018 Aug 16] Available from: https://labour.gov.in/annual-reports

8. Manjunatha R, Kiran D and Thankappan K. Sickness Absenteeism, Morbidity and Workplace Injuries among Iron and Steel Workers-a cross-sectional study from Karnataka, Southern India. Australas Med J. 2011; 4:144-147. https://doi.org/10.4066/AMJ.2011.576

9. Sickness benefit procedure. In: Director General, editor. ESIC Branch office manual, $4^{\text {th }}$ edition. New Delhi: ESIC Publications;2010. p. 339-346.
10. Pandey VK, Aggarwal P and Kakkar R. Modified BG Prasad Socio-economic Classification, Update - 2019. Indian J Comm Health. 2019; 31: 123-125.

11. Gimeno D, Benavides FG, Benach J and Amick BC. Distribution of sickness absence in the European Union countries. Occup Environ Med. 2004;61(10):867-869.

https://doi.org/10.1136/oem.2003.010074

12. Tiwari R. A study on causes of Absenteeism among NonExecutive Employees of a Flagship Steel Manufacturing industry. International Journal for Research in Engineering Application \& Management. 2018; 4:487-491.

13. Jayapriya $D$ and Rathika S. A study on employee absenteeism in the stainless steel utensils manufacturing industry. International Journal of Advance Research and Innovative Ideas in Education. 2020; 6:1216-1223.

14. Oenning NSX, Carvalho FM and Lima VMC. Risk factors for absenteeism due to sick leave in the petroleum industry. Rev Saúde Pública.2014; 48:103-112. https://doi.org/10.1590/S0034-8910.2014048004609

15. Mekonnen TH, Lamessa SK, and Wami SD. Sickness-related absenteeism and risk factors associated among flower farm industry workers in Bishoftu town, Southeast Ethiopia, 2018: a cross-sectional study. BMC Res Notes [Internet]. 2019 Mar[cited 2020 Jan 15]; 181(12):[about 7 p]. Available from: https://www. bmc.org/BMC/2019/Mar/Wawatch.htm.article

16. Wee LH, Yeap LLL, Chan CMH, Wong JE, Jamil NA, Swarna Nantha $Y$, et al. Anteceding factors predicting absenteeism and presenteeism in urban area in Malaysia. BMC Public Health. 2019;19(Suppl 4):540.

https://doi.org/10.1186/s12889-019-6860-8

17. Chakraborty $\mathrm{S}$ and Subramanya $\mathrm{AH}$. Socio-demographic and clinical predictors of absenteeism A cross-sectional study of urban industrial employees. Industrial Psychiatry J. 2013; 22:17-21. https://doi.org/10.4103/0972-6748.123589

\section{Author's Contribution:}

SB-Concept, design of the study, preparation of manuscript; RK- coordinating with factory in charges; HP- Revision of manuscript. All authors approved the final version of the manuscript.

Work attributed to:

ESIC Medical College \& hospital, Hyderabad, Telangana state, India.

Orcid ID:

Dr. Sudha Bala- (D) https://orcid.org/0000-0001-7616-1132

Dr. Harshal Pandve- https://orcid.org/0000-0002-0400-3589

Source of Funding: None, Conflict of Interest: None 